\title{
İkinci basamak hastanede perkütan endoskopik gastrostomi deneyimlerimiz
}

\author{
Percutaneous endoscopic gastrostomy: Experience in a secondary level hospital
}

\author{
Abdullah ŞENLIKÇİ ${ }^{1}$, Ufuk Barış KUZU², Fatma DEDE ${ }^{3}$, Kerime FIDAN ${ }^{1}$ \\ Bitlis Devlet Hastanesi, ${ }^{1}$ Genel Cerrahi Kliniği, ${ }^{2}$ Gastroenteroloji Kliniği, ${ }^{3}$ Radyoloji Bölümü, Bitlis
}

\begin{abstract}
Giriş ve Amaç: Perkütan endoskopik gastrostomi, herhangi bir nedenle oral yoldan beslenemeyen ve gastrointestinal sistemi sağlam olan hastalarda enteral beslenmenin sağlandiğı en güvenli gastrostomi çeşididir. Bu çalışmadaki amacımız 2. basamak hastanemizdeki perkütan endoskopik gastrostomi takılma endikasyonlarını, işlem sonrası erken ve geç dönem komplikasyonlarını ve takipleri ile ilgili verileri sunmaktır. Gereç ve Yöntem: Bitlis Devlet Hastanesi endoskopi ünitesinde Eylül 2016-Ekim 2017 tarihleri arasında perkütan endoskopik gastrostomi tüpü takılan hastalar retrospektif olarak incelendi. Bulgular: Çalışmaya 26 olgu dahil edildi. Olguların yaş ortalamas 64,23 (18-101) idi. Olguların 13'ü erkek ve 13'ü kadın idi. Olguların 11'ine $(\% 42,3)$ serebrovasküler hastalık, 5'ine $(\% 19,23)$ demans, 3'üne $(\% 11,53)$ amyotrofik lateral skleroz, I'ine $(\% 3,84)$ nöro-Behçet, I'ine $(\% 3,84)$ hidrosefali, l'ine $(\% 3,84)$ akromegali, l'ine $(\% 3,84)$ elektrik yanığ, l'ine $(\% 3,84)$ Erb-Duchanne Musküler distrofisi, l'ine $(\% 3,84)$ serebral palsi ve l'ine $(\% 3,84)$ epidural kanama nedeniyle perkütan endoskopik gastrostomi yapıld1. Olguların ortalama takip süresi 137,65 (4-388) gündür. 2 (\%11,53) olguda erken dönem komplikasyon gözlendi. Bir olguda batın içi serbest hava ve bir olguda da üst gastrointestinal sistem kanaması gözlendi, ek olarak bir hastamızda, uyumsuzluk nedeniyle perkütan endoskopik gastrostomi kanülünü çekerek çıkardığı gözlendi. Işleme bağlı mortalite gözlenmemiştir. 1 aylık mortalite oranımı \%3,8 ve 3 aylık mortalite oranımız ise \%26,9'dur. Sonuç: Perkütan endoskopik gastrostomi enteral beslenme amacıyla yapılan gastrostominin en güvenilir yoludur. 2. basamak hastanelerde de güvenle uygulanabilir.
\end{abstract}

Anahtar kelimeler: Perkütan endoskopik gastrostomi, endikasyon, komplikasyon

\section{GIIRISS}

Perkütan endoskopik gastrostomi (PEG) çeşitli sebeplerle disfaji gelişen hastalarda enteral beslenme için güvenli bir yol olarak geliştirilmiştir. Ameliyathane şartları gerektirmemektedir. Lokal anestezi ve sedasyon altında yapılabilmesi, kısa sürede, etkin bir yöntem olması nedeniyle günümüzde tercih edilen bir yöntemdir. PEG'in geliştirilmesiyle birlikte gastrostomi açılması kolaylaşmış ve oral beslenme zorlaştığında sıkça kullanılmaya başlamıştır (1). PEG prosedürü ilk olarak 1980 yılında enteral beslenme için efektif ve cerrahi gastrostomi açılmasına alternatif bir metod olarak Gauderer ve arkadaşları tarafından geliştirilmiştir (2). PEG için en sık görülen endikasyonlar serebrovasküler hastalıklar, motor-nöron hastalıklar, kanser ve baş ve boyuna travmadır (3). PEG'in aspirasyon pnömonisi, PEG yeri enfeksiyonu, tüp çıkması,
Background and Aims: Percutaneous endoscopic gastrostomy is the safest approach to enteral feeding in patients with an intact gastrointestinal system that cannot be fed orally. In this study, we assessed percutaneous endoscopic gastrostomy indications, complications, and follow-up data in our secondary level hospital. Materials and Methods: This was a retrospective study with patients that had a percutaneous endoscopic gastrostomy tube placed between September 2016 and October 2017 in the endoscopic unit at Bitlis State Hospital. Results: Twenty-six patients were included in the study. Patients mean age was 64,23 years (18-101). Percutaneous endoscopic gastrostomy was performed in 11 (42.3\%) patients due to cerebrovascular disease, in $5(19,23 \%)$ patients due to dementia, in $3(11,53 \%)$ patients due to amyotrophic lateral sclerosis, in $1(\% 3,84)$ patient due to neuro-Behçet's disease, in 1 (3,84\%) patient due to hydrocephalus, in $1(3,84 \%)$ patient due to acromegaly, in $1(\% 3,84)$ patient due to electricity burn, in $1(3,84 \%)$ patient due to Erb-Duchenne Muscular dystrophy, in $1(\% 3,84)$ patient due to cerebral palsy, and in $1(3,84 \%)$ patient due to epidural hemorrhage. The mean follow-up period was 137.65 (4-388) days and 3 (11.53\%) patients had complications: tube ejection, free air in the abdomen, and upper gastrointestinal bleeding. No post-procedural mortality was observed, at 1-month mortality rate was $3.8 \%$, and the 3 -month mortality rate was $26.9 \%$. Conclusion: Percutaneous endoscopic gastrostomy is the safest type of gastrostomy for enteral feeding. Percutaneous endoscopic gastrostomy can be performed safely in secondary level hospitals.

Key words: Percutaneous endoscopic gastrostomy, indication, complication

gastrik perforasyon, kolokütanöz fistül gibi birçok erken ve geç komplikasyonu olmasına rağmen yutma güçlüğü olan hastalarda enteral nütrisyonu sağlamak için en sık kullanılan yöntemdir. Kullanımı kolay olduğu için hasta yakınları kolaylikla eğitilebilirler (4).

Bu çalışmadaki amacımız 2. basamak hastanede PEG takılan hastaların PEG takılma endikasyonlarını, işlem sonrası erken ve geç komplikasyonlarını, takipleri ile ilgili verilerini sunmaktır.

\section{GEREC ve YÖNTEM}

Eylül 2016-Ekim 2017 tarihleri arasında yoğun bakım ünitesinde ya da palyatif bakım ünitesinde yutma ya da ögürme 
refleksinin olmadığı nöroloji hekimince tespit edilen ve perkütan endoskopik gastrostomi uygulanan 26 hasta retrospektif olarak değerlendirildi. Hastalara ait yaş, cinsiyet, primer hastalıkları, takılma sebebi, işlem komplikasyonları, işlem ile ilgili morbidite ve mortalite kaydedildi. PEG endikasyonu konulan tüm hastaların rutin laboratuvar tetkikleri işlem öncesi incelendi. Tüm olgulara proflaktik antibiyotik uygulandı. Tüm hastalar kanama hastalıkları [uluslararası normallenmiş oran (INR): <1.5, Platelet (Plt): <50,000], gastroskopi işlemine engel olabilecek patoloji, batında yaygın asit, gastointestinal obstrüksiyon gibi kontrendikasyonlar açısından değerlendirildi. Tüm olgular işlem sırasında periferik oksijen satürasyonu, elektrokardiyografi (EKG), sistolik ve diastolik kan basınçları sürekli olarak izlendi. Tüm olgulara anestezi hekimi takibinde sedasyon uygulandı. Nazogastrik yoldan enteral beslenen hastalarm beslenmeleri 12 saat önceden kesildi. Her hastaya işlemden 2-4 saat öncesinde profilaktik antibiyoterapi verildi. Işlem "Pull" tekniği kullanılarak, sterilizasyona dikkat edilerek, "Flowell Perkütan Endoskopik Gastrostomi Tüpü 16 fr" ile gerçekleştirildi. Işlemde PEG uygulamasından sonra 24 saat kadar da olgularda enteral yol kullanılmadı.

\section{BULGULAR}

Olguların yaş ortalaması 64,23 (18-101) idi. Olguların 13'ü erkek, 13 'ü kadın idi. Olguların 11'ine $(\% 42,3)$ serebrovasküler hastalık, $5^{\prime}$ ine $(\% 19,23)$ demans, 3'üne $(\% 11,53)$ amyotrofik lateral skleroz (ALS), l'ine $(\% 3,84)$ nöro-Behçet, l'ine $(\% 3,84)$ hidrosefali, l'ine $(\% 3,84)$ akromegali, l'ine $(\% 3,84)$ elektrik yanığı, l'ine $(\% 3,84)$ Erb-Duchanne Musküler distrofisi, l'ine $(\% 3,84)$ serebral palsi ve l'ine $(\% 3,84)$ epidural kanama nedeniyle perkütan endoskopik gastrostomi yapıldı (Tablo 1). Olguların hepsine PEG başarı ile uygulandı. Iki hastanın özgeçmişinde batın operasyonu öyküsü mevcuttu. Olguların ortalama takip süresi 137,65 (4-388) gündü. PEG

\begin{tabular}{lcc} 
Tablo 1. Etyolojilerine göre olguların dağılımı & \\
\hline Primer Hastalık & Hasta sayısı & $\%$ \\
\hline Serebrovasküler Hastalıklar & 11 & 42,3 \\
\hline Demans & 5 & 19,23 \\
\hline ALS & 3 & 11,53 \\
\hline Hidrosefali & 1 & 3,84 \\
\hline Akromegali & 1 & 3,84 \\
\hline Elektrik Yanığı & 1 & 3,84 \\
\hline Erb-Duchenne Musküler Distrofisi & 1 & 3,84 \\
\hline Nörobehçet & 1 & 3,84 \\
\hline Serebral palsi & 1 & 3,84 \\
\hline Epidural kanama & 1 & 3,84
\end{tabular}

ALS: Amyotrofik lateral skleroz.

\begin{tabular}{|lcr|}
\hline Tablo 2. Kliniklere göre dağılım & \\
\hline Klinik & Hasta Sayısı & $\%$ \\
\hline Nöroloji servisi & 11 & 42,3 \\
\hline Yoğun bakım & 11 & 42,3 \\
\hline Palyatif bakım & 4 & 15,3 \\
\hline
\end{tabular}

uygulanan olguların 1l'i $(\% 42,3)$ nöroloji servisinde, 11'i $(\% 42,3)$ yoğun bakımda ve 4'ü de $(\% 15,3)$ palyatif bakım servisinde yatmaktaydı (Tablo 2). Iki olguda $(\% 7,6)$ komplikasyon gözlendi. Ilk hastada, post-operatif birinci günde direk grafi ve batın bilgisayarlı tomografisinde batın içi yaygın serbest hava gözlendi (Şekil 1,2). Pnömoperitoneum tanısı ile

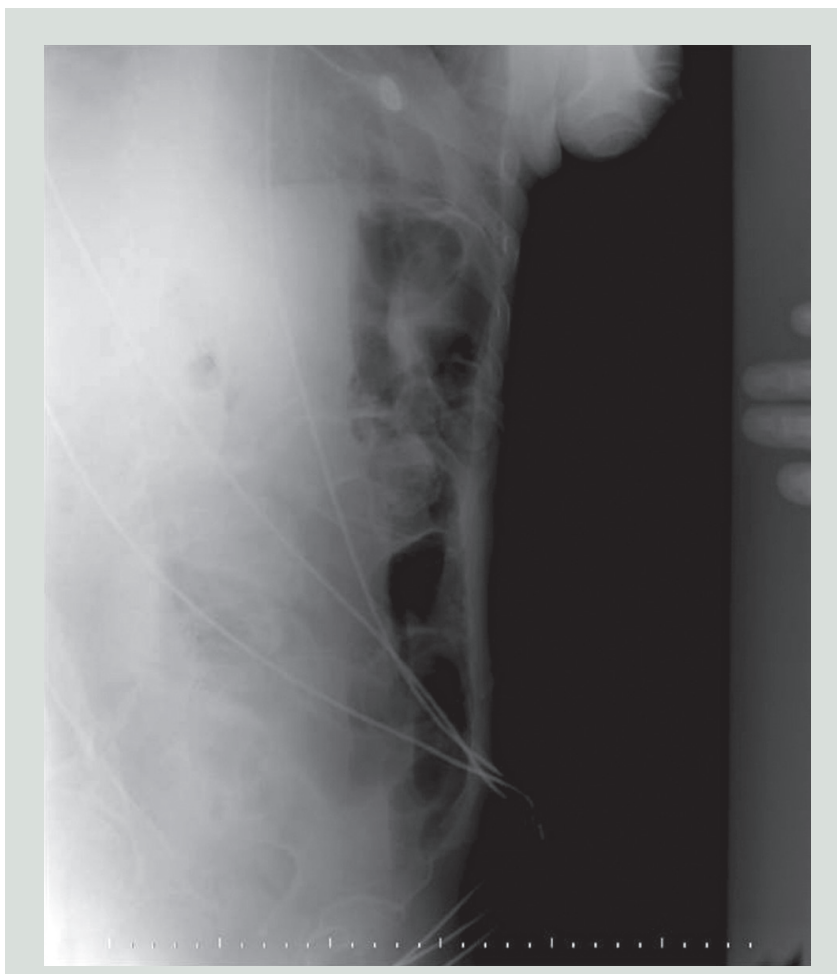

Şekil 1. Batın içi yaygın serbest hava (direkt grafi).

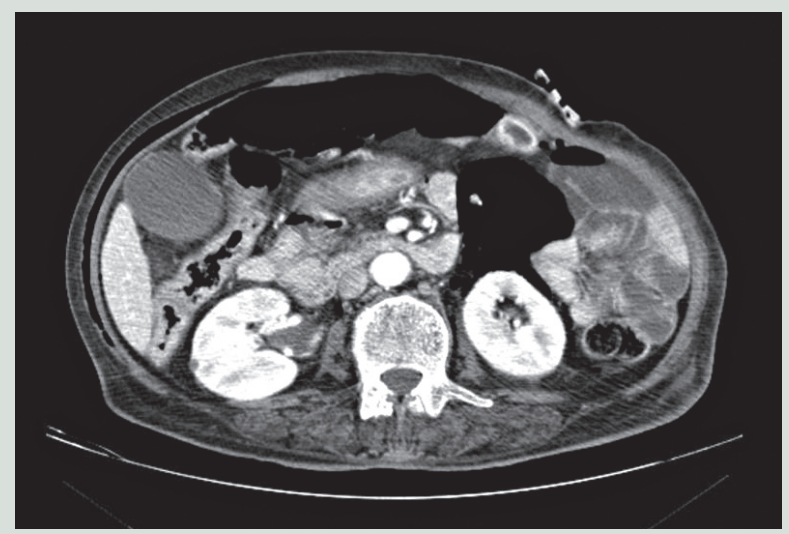

Şekil 2. Batın bilgisayarlı tomografisinde batın içi yaygın serbest hava. 
Tablo 3. PEG komplikasyon dağılımı

\begin{tabular}{|lc} 
Komplikasyon & $\begin{array}{c}\text { Erken Dönem } \\
\text { Komplikasyon }\end{array}$ \\
\hline Batın içi serbest hava (Pnömoperitonium) & 1 \\
\hline Üst GIS kanama & 1 \\
& $\% 7,6$
\end{tabular}

PEG: Perkütan endoskopik gastrostomi, GIS: Gastrointestinal sistem

takip edilen hasta konservatif olarak tedavi edildi. Hastanın cerrahi gereksinimi olmadi. Diğer hastada ise işlemden 4 saat sonrasinda üst gastrointestinal kanama gözlendi. Bu olguda da konservatif takip sonrasında cerrahi gereksinim gözlenmedi (Tablo 3). Ek olarak bir hastamız da, uyumsuzluk nedeniyle PEG takılmasının 79. ve 2. takılmanın 14. gününde PEG kanülünü çekti. Her ikisinden sonra da PEG kanülü aynı yerden endoskopik olarak tekrar takılmıştır. Olguların dokuzunda takip süresinde işlemden bağımsız sebeplerden ötürü exitus gözlenmiştir. 17 olgunun takipleri devam etmektedir.

\section{TARTIȘMA}

PEG, herhangi bir nedenle ağıdan beslenemeyen, gastrointestinal fonksiyonları normal olan ve 4 haftadan daha uzun süre enteral beslenme ihtiyacı olan hastalara uygulanan bir beslenme tekniğidir (5). Perkütan endoskopik gastrostomi ile mukozal bütünlük korunur ve normal flora yapısının devamı sağlanır. Gastrostomi; cerrahi, radyolojik ve endoskopik olmak üzere 3 farklı şekilde yapılabilir (6). Bankhead ve ark. yaptıkları bir çalışmada en az perkütan endoskopik yöntemin, daha sonra açık cerrahi yöntemin, en fazla da laparoskopik yöntemin komplikasyon oranı olduğunu ve PEG'in en iyi seçenek olduğunu bildirmişlerdir (7). Cerrahi gastrostomi yöntemlerine göre PEG işleminin morbidite ve mortalitesinin az olması, genel anestezi gerektirmemesi, yatak başında bile uygulanabilmesi, maliyetinin düşük olması nedeniyle daha fazla tercih edilmektedir (8).

Serebrovasküler olaylar, beyin travması, bulber parezi, Parkinson hastalığı, amyotrofik lateral sklerozis, serebral palsi, nöromüsküler hastalıklar, baş-boyun ve özofagus tümörleri, politravma ve uzun süreli koma hali PEG endikasyonları arasındadır. PEG uygulanan hastaların büyük çoğunluğunu nörolojik hastalığı olan hastalar oluşturur. Ekin ve arkadaşlarının yaptığı çalışmada da olguların \%93"ünde nörolojik rahatsızlıklar mevcuttu (9). Bizim çalışmamızda da olguların \%92,3'ünde nörolojik rahatsızlıklar mevcuttu.

PEG'e bağlı olarak \%4-13,6 oranında komplikasyon görülebilmektedir. Bu komplikasyonların başlicaları; gastro-kolik fistül, peritonit, hemoraji ve enfeksiyondur (10). Zopf ve arkadaşları PEG sonrası komplikasyon ve enfeksiyon için 4 risk faktörü tanımlamışlardır; uygulanan hastane, PEG tüpünün boyutu, endoskopistin deneyimi ve altta yatan malign bir hastalık olması (11). Akkersdijk ve arkadaşları pull tekniği ve profilaktif antibiyotik kullanımının işlemle ilgili komplikasyonları ve bölgesel enfeksiyon olasılığını azalttığını belirtmişlerdir (12). Literatürde işlem öncesi profilaktik antibiyotik tedavisinin yararlı olup olmadığı konusunda görüş birliği hala mevcut değildir. Boyacı ve arkadaşlarının yaptığı çalışmada da profilaktik antibiyotik kullanımının etkinliği gösterilememiştir. Bizim çalışmamızda işlem öncesi hastalarımıza profilaktik antibiyoterapi tedavisi uyguladık. Bölgesel enfeksiyon hiç bir olguda gözlenmedi. 2 (\%7.6) olguda komplikasyon gözlendi.

PEG işlemine bağlı mortalite \%l'in altında bildirilmiştir. Yapılan çalışmalarda ilk 30 günlük mortalite oranları işlem dışı nedenlere bağlı, değişik serilerde \%8 ile \%26,8 arasında, 3 aylık mortaliteleri de \%15,7 ile \%42 arasında olduğu belirtilmiştir (8). Bizim çalışmamızda işleme bağlı mortalite gözlenmemiştir. Düşük serum albümin düzeyi PEG takılması sonrasında mortaliteyle ilişkili bir risk faktörü olarak bildirilmiştir. Diğer bilinen prognostik faktörler ise düşük kolesterol seviyesi, düşük lenfosit sayısı, hiponatremi ve kardiyovasküler hastalıklar gibi komorbid hastalıklardır (13).

Sonuç olarak; PEG enteral beslenmenin en güvenilir yoludur. Yirmi altı hastayı içeren çalışmamız incelendiğinde, elde edilen sonuçlar ve görülen komplikasyonlarda literatürle belirgin farklar gözlenmemektedir. Deneyimli ekip tarafından yapıldığında basit, güvenli, kısa sürede yapılabilen, enfeksiyon ve diğer komplikasyon oranları açısından düşük, etkili bir enteral beslenme yöntemidir. PEG 2. basamak hastanelerde de güvenle uygulanabilir.

\section{KAYNAKLAR}

1. Kusano C, Yamada N, Kikuchi K, et al. Current status of percutaneous endoscopic gastrostomy (PEG) in a general hospital in Japan: a cross-sectional study. J Rural Med 2016;11:7-10.

2. Gauderer MW, Ponsky JL, Izant RJ Jr. Gastrostomy without laparotomy: a percutaneous endoscopic technique. J Pediatr Surg 1980;15:872-5.

3. Gundogan K, Yurci AM, Coskun R, et al. Outcomes of percutaneous endoscopic gastrostomy in hospitalized patients at a tertiary care hospital in Turkey. Eur J Clin Nutr 2014;68:437-40.

4. Makwana HB, Kansal SV, Baldha M, Agarwal S. Percutaneous endoscopic gastrostomy: Four years of experience of general surgery department at a tertiary care center at Surat. Int J Sci Stud 2016;4:171-4.

5. Temiz A, Aslan OB, Albayrak Y, et al. Percutaneous endoscopic gastrostomy: indications and complications. Akademik Gastroenteroloji Dergisi 2015;14:113-6.

6. Senol Z, Karakas DÖ, Yilmaz I, et al. Perkütan endoskopik gastrostomi tecrübemiz: 64 olgunun değerlendirilmesi. Van Tıp Dergisi 2013;20:52-6. 
7. Bankhead RR, Fisher CA, Rolandelli RH. Gastrostomy tube placemen outcomes: comparison of surgical, endoscopic and laparoscopic methods. Nutr Clin Pract 2005;20:607-12.

8. Sit M, Kahramansoy N, Tekelioglu UY, Ocak T. Our experience in percutaneous endoscopic gastrostomy. JAREM 2013;3:66-8.

9. Ekin N, Ucmak F, Oruc M, et al. Perkütan endoskopik gastrostomi uygulama sonuçlarımız: 113 olgunun değerlendirilmesi. Dicle Med J 2015;42:346-9

10. Akay MA, Yayla D, Elemen L, et al. Percutaneous Endoscopic Gastrostomy; Experience of two clinics. Sakaryamj 2014;4:70-3.
11. Zopf Y, Konturek P, Nuernberger A, et al. Local infection after placement of percutaneous endoscopic gastrostomy tubes: a prospective study evaluating risk factors. Can J Gastroenterol 2008;22:987-91.

12. Akkersdijk WL, van Bergeijk JD, van Egmond T, et al. Percutaneous endoscopic gastrostomy (PEG): comparison of push and pull methods and evaluation of antibiotic prophylaxis. Endoscopy 1995;27:313-6.

13. Sarkar P, Cole A, Scolding NJ, Rice CM. Percutaneous endoscopic gastrostomy tube insertion in neurodegenerative disease: A retrospective study and literature review. Clin Endosc 2017;50:270-8. 